\title{
The Physiology and Biochemistry of the Digestion System of Termites from the Genus Anacanthotermes Jacobson, 1904
}

\author{
Ikram I. Abdullaev ${ }^{1}$, Manzura B. Doschanova ${ }^{1}$, Zafar Sh. Matyakubov², Abdulla I. Iskandarov², \\ \& Feruza R. Rakhimbaeva ${ }^{2}$ \\ ${ }^{1}$ Khorezm Academy of Mamun, Khiva, Uzbekistan \\ ${ }^{2}$ Urgench State University (UrSU), Urgench, Uzbekistan \\ Correspondence: Ikram Abdullaev, Chairman Khorezm Academy of Mamun, 220900, Khiva, Uzbekistan. Tel: \\ 998-362-375-8051. E-mail: a_ikrom@mail.ru
}

Received: June 12, 2019

Accepted: July 5, 2019

Online Published: July 9, 2019

doi:10.5539/ijb.v11n4p1

URL: https://doi.org/10.5539/ijb.v11n4p1

\begin{abstract}
A variety of morphological and functional features of the digestive system of termites is associated with their nutritional adaptation. Wood is mostly the food of termites' adult larvae, workers and young nymphs. The salivary and intestinal enzymes play an important part in this process. The physiology and biochemistry of the digestion system of termites from the genus Anacanthotermes is still not fully studied. In the present research, we studied the activity of some carbohydrases in termites' salivary glands. Our data show that the activity of exocellulase in adult termites is 1.5 times more that in young individuals and 3 times more active than in nymphs, while the exocellulase in soldiers remains inactive. Moreover, the activity of celluloses in the intestine of A. turkestanicus is still not fully studied. We observed that exocellulase is involved in the digestion of food polymers in the castes of termites-workers, nymphs and soldiers. Thus, cellulase activity in the intestinal tissue (intrinsic) is manifested at a very low level in all termites' castes we studied. However, the activity of exocellulase in the intestinal cavity (symbiotic) increases 3.5 times in workers, 3.0 times in nymphs and 2.4 times in soldiers compared to that in intestinal tissue. In addition, the intrinsic activity of this enzyme differed little in all three castes of termites, whereas the symbiotic activity in workers and nymphs was more showed than in soldiers.
\end{abstract}

Keywords: Exocellulase, Termites, Isoptera, Hemolymph

\section{Introduction}

The physiology and biochemistry of termites were investigated in irrigated and arid Land in the Aral Sea Basin in Central Asia. Termite-related damage in buildings of this region was monitored (including ancient constructions in historical town of Khiva, now a UNESCO cultural heritage site) (Abdullaev et al., 2002). The termites of the Isoptera order are small or medium-sized insects, usually avoiding light and living in families in special nests built in the ground, wood, or constructed from a special cardboard-like material (Gilyarov et al., 1984; Legendre et al., 2013). According to estimates by entomologists, the Isoptera unit includes from 2,000 to 2,900 species (Luppova, 1973; Krishna et al., 2013). There are only 7 species of termites in the CIS, which are representatives of four families Alfred (1980).

The famous cities of Central Asia such as Bukhara, Samarkand and Khiva, situated in the territory of the Republic of Uzbekistan, are home to several historical monuments of great cultural importance. Most of the monuments in Khiva (Figure 1) located in the Khoresm province in the western part of Uzbekistan are severely damaged by termites particularly the harvester termite, Anacanthotermes ahngerianus (Khamraev et al., 2004, 2006).

One family of termites out of 25 thousand individuals living in $100 \mathrm{~cm}^{3}$ of volume per year consumes on average up to $50,000 \mathrm{~cm}^{3}$ of various types of cellulose (Baeva et al., 1993). At the same time, all this leads to a global carbon cycle and an increase of the concentration of greenhouse gas in the atmosphere-carbon dioxide. All this is done through the digestive secretions of termites and symbiotic enzymes, as well as through the activity of biochemical processes (Sapunov, 2008). In termites, the volume of the digestive tract is 108 times smaller than the rumen of ruminants, and at the same time it has a significantly larger surface area per unit volume. If we assume that the intestine is spherical, then it is not difficult to calculate that the termites' oxygen supply per unit volume will be approximately 500 times higher than that of ruminants (Brune, 1998). 


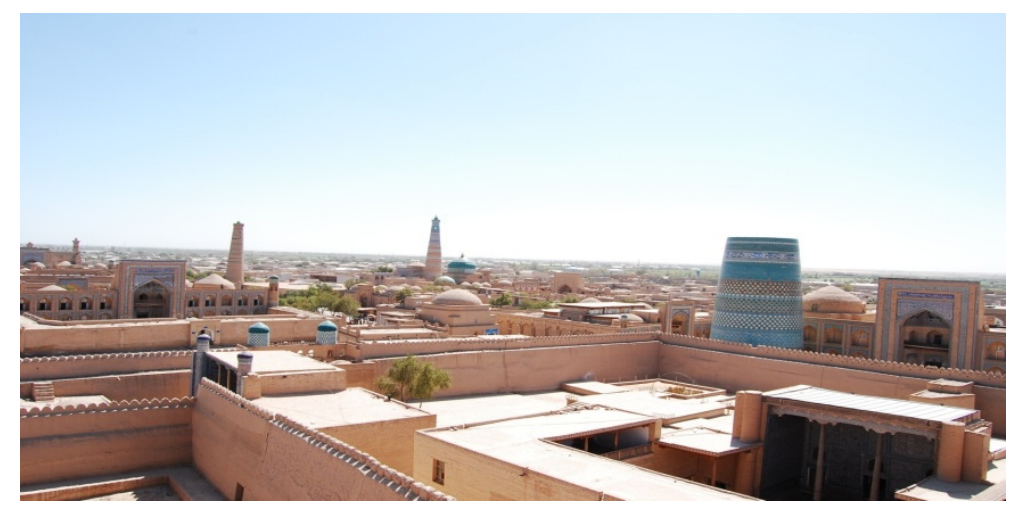

Figure 1. View of the historic Khiva. The fortress containing 57 buildings is surrounded by a very thick mud wall

Enzymes involved in the digestion of animals, including the insects in question, belong exclusively to the hydrolytic type. In different groups of animals, the set of digestive enzymes varies greatly, reflecting the complex nature of the influence of adaptation to different types of food and the evolutionary origin (Ugolev, 1985). The aim is to determine the activity of enzymes in the salivary and intestinal glands of termites to protect the wood material from termites of the genus Anacanthotermes, and to determine termite-resistant wood materials.

Based on this, the tasks of studying the system of exo- and endocellulases, determining the causes of wood damage by termites, establishing the activity of carbohydrase and symbiotic enzymes in the saliva and glands of the intestine, studying the activity of carboxymethylcellulase and cellobiasis in the salivary glands of all castes of termites were identified. The significance of the study is that the data on the determination of the activity of lactase and other enzymes in the salivary glands of termites of the genus Anacanthothermes are identified as the physiology of termites. Our data will be helpful for the better understanding of identifying wood materials that are resistant to damage from termites and their use in residential buildings and other objects in future.

\section{Materials and Methods}

This work was based on qualitative and quantitative collections of termites from natural and urbanized ecosystems, conducted in the North-Western and Central regions covering the territory of Khorezm region, the Republic of Karakalpakstan, Samarkand, Bukhara, Navoi regions of Uzbekistan.

Routing research methods covered, practically, all regions of the republic. Termites in the genus Anacanthotermes were collected by generally accepted entomological methods (Raina et al., 2003; Weidner, 1960).

There were collected and studied in total 10525 examples of two types of termites - Anacanthotermes ahngerianus Jacobson, 1904 and A. turkestanicus Jacobson, 1904. with the help of the "Exterra" apparatus (Figure 2).

To solve a number of issues related to the vital activity of termites Anacanthotermes ahngerianus and A. turkestanicus, were used generally accepted methods (Skirkyavichyus, 1986).

To identify the participation of the enzymes of the salivary glands of various castes of termites, large and small working termites, soldiers and nymphs A. ahngerianus and A. turkestanicus from the "Khiva" farm of the Khorezm region were used. In the laboratory, before testing, insects were kept in plastic containers at $80-100 \%$ humidity and room temperature with natural light and with a moistened filter paper as a food source (Figure 3).

In termites (older and younger workers, nymphs, soldiers), after weak chloroform anesthesia, the heads were cut off, cleaned them of periostracum under a Leica CLS (Switzerland) light microscope, and salivary glands were isolated from them. The obtained biological samples were diluted with acetate buffer $(\mathrm{pH}=4.5)$ at a ratio of 1:10. In one sample for the biochemical analysis were combined preparations of 60 termites. For the analysis of each enzyme were used $5(\mathrm{n})$. The obtained mixture was homogenized with a Teflon pistil at a speed of $400 \mathrm{rpm} / \mathrm{min}$. In the obtained homogenate, the activity of $\alpha$-amylase was determined by the method of Ugolev and Iezuitova (1969), as well as exocellulase, carboxymethylcellulase, cellobiase, maltase, sucrase, and lactase, glucose oxidase, by means of the sample, resulting from the hydrolysis of glucose, using a set of "Gluco-Fen".

To clarify the characteristics of cellulose digestion in various castes of the Turkestan termite, were used large workers, soldiers and nymphs $A$. turkestanicus. 
The intestines were further used to determine the activity of cellulases of intestinal tissue, i.e. activity of its own enzymes, and rinse-to determine the activity of enzymes produced by microorganisms, i.e. activity of enzymes of symbiotic origin. Enzyme activity was determined by the method of Ugolev and Iezuitova (1969), expressing it in $\mu \mathrm{g} / \mathrm{min}$ of glucose formed per termite.

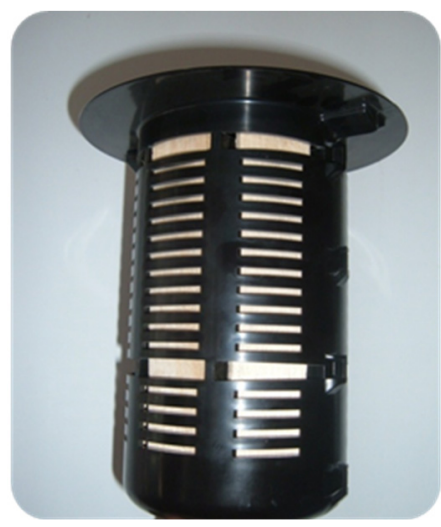

Figure 2. Apparat Exterra

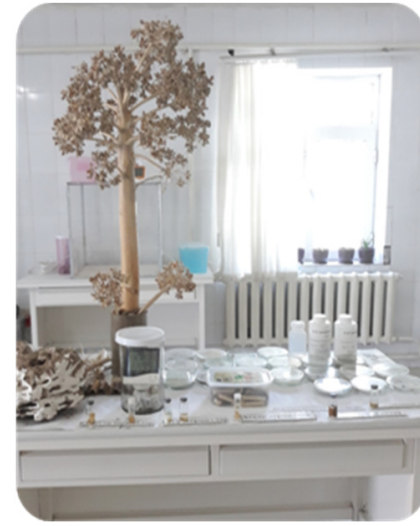

Figure 3. plastic containers

\section{Results and Discussion}

All animals (with the exception of parasites) use a set of specific macromolecules or other complex components as essential nutrients. In order for these substances to be involved in metabolism, it is necessary to break them down into simple forms with the help of special enzymes. Enzymes involved in the digestion of animals, including the insects in question, belong exclusively to the hydrolytic type.

One of the main means of general feeding is called trophallaxis or mutual exchange of intestinal contents between members of a colony. Trophallaxis also makes it possible to efficiently use nutrients, recognition by colony members, the distribution of chemicals involved in caste regulation, and the transfer of cellulose to protozoaires digestion. Many members of the termite colony cannot feed themselves, so they rely on other colony members to feed them. This behavior also facilitates the transfer of toxicants used in bait and other insecticides.

\subsection{Enzymes of the Salivary Glands of Termites in the Genus Anacanthotermes and Their Role in Digestion}

A variety of morphological and functional features of the digestive system of termites is associated with their food specialization. Treated termites feed on wood. This food is eaten by working individuals, larvae of older ages, nymphs of younger ages. Soldiers, larvae of younger ages and reproductive individuals receive already partially processed food from workers.

At the same time, saliva is a direct participant in the exchange processes occurring between individuals of different castes. Considering that the first hydrolytic barrier to which food is exposed, trapped in the oral cavity of termites, is the secret of the salivary glands.

Results for determining the activity of carbohydrate digestion hydrolases of termites of different castes are presented in Table 1.

The activity of exocellulase was determined as an enzyme of the initial stage of cellulose hydrolysis. It turned out that exocellulase is involved in the digestion of food polymers in workers, nymphs, but not soldiers. The highest activity of exocellulase was observed in working termites. At the same time, it was more expressed for older workers than for younger workers. The exocellulase activity of the older workers was 1.5 and 3.0 times higher than that of the younger workers and nymphs, respectively.

Despite the fact that the main food of termites is cellulose, the activity of the enzyme involved in the initial stages of its digestion, i.e. exocellulase, was expressed by 10-20 times less as compared to another carbohydrase, $\alpha$-amylase, splitting starch.

A-amylase activity also had caste specificity. Her activity among younger workers, nymphs and soldiers was 1.5 , 2.1 and 2.5 times lower, respectively, compared to older workers. 
Table 1 . The activity of some carbohydrases in the salivary glands of termites $(M \pm m, n=5)$

\begin{tabular}{lllll}
\hline $\begin{array}{l}\text { Carbohydrases activity } \\
\mu \mathrm{mol} / \mathrm{min} / \mathrm{g} \text { tissue }\end{array}$ & Big workers & Small workers & Nymphs & Soldiers \\
\hline Exocellulasic & $0.09 \pm 0.01$ & $0.06 \pm 0.004$ & $0.03 \pm 0.01$ & $0.01-0.05$ \\
Amylase & $9.15 \pm 0.5$ & $6.30 \pm 0.03$ & $4.32 \pm 0.07$ & $3.71 \pm 0.06$ \\
Carbobossimetilcellulosic & 0 & 0 & 0 & 0 \\
Cellobiase & 0 & 0 & 0 & 0 \\
Maltase & $1.16 \pm 0.02$ & $1.07 \pm 0.02$ & $1.00 \pm 0.02$ & $1.06 \pm 0.02$ \\
Saccharase & $1.05 \pm 0.03$ & $0.95 \pm 0.08$ & $1.00 \pm 0.06$ & $1.05 \pm 0.05$ \\
Lactase & $2.10 \pm 0.03$ & $2.2 \pm 0.16$ & $1.7 \pm 0.14$ & $1.9 \pm 0.09$ \\
\hline
\end{tabular}

The activity of carboxymethylcellulase and cellobiase enzymes involved in the hydrolysis of cellulose products, i.e. the final stages of its splitting were absent altogether.

Maltase. The activity of the disaccharidase involved in the hydrolysis of the dimer formed during the splitting of starch was found in all studied representatives of termites castes. No caste specificity was found. Approximately the same activity was manifested in sucrase, i.e. it was on the same level with all castes of termites.

Concerning lactase, which is involved in the digestion of milk sugar, it can only be noted that it was almost 2 times more than the activity of other enzymes.

The salivary glands of most insects function closely with the organs of nutrition, therefore the enzyme composition of saliva depends on the food regime of insects. The salivary glands do not contain symbionts, all the enzymes found in them have their own origin. A number of studies have shown that gland extracts of working termites of many species can hydrolyze a significant number of oligo- and polysaccharides, as well as heterosides, but these studies did not pay attention to other termite castes (Khamraev et al., 2010). We have shown that in the salivary glands of A. turkestanicus there are hydrolytic systems involved in the initial and final stages of carbohydrate hydrolysis.

From the data obtained it is clear that those enzymes that are involved in the initial stages of the hydrolysis of macromolecules, namely $\alpha$-amylase and exocellulase, are more expressed in workers compared to representatives of other castes. Polymer digestion has a caste expression and weakens in the series: senior workers-younger workers, nymphs, soldiers.

The enzymes involved in the final stages of carbohydrate hydrolysis in the salivary glands of termites are expressed ambiguously. Hydrolases, completing the cleavage of cellulose (carboxymethylcellulase, cellobiasis), are absent. Meanwhile, disaccharidases that do not decompose cellulose hydrolysis products: maltase, sucrase and lactase are detected. It is possible that the latter are involved in the digestion of not only the dimers of the termites natural poverty, but also the food that is partially processed by the microorganisms of the intestine, which can get to them during its transit from termite to termite during oral or caprophagal transmission.

It was shown that in the salivary glands, in addition to the presence of some exocellulase activity, a rather high activity of $\alpha$-amylase is manifested, as well as some activity of disaccharidases such as maltase, sucrase, and lactase, which do not participate in the digestion of the main food component of insects-cellulose.

This suggests that in the oral cavity of termites is hydrolyze only of easily digestible products, and more difficultly hydrolyzable, for example, cellulose, most likely undergoes digestion in the medial and distal parts of the alimentary canal with symbiotic organisms. We have previously shown that in the cavity of the small intestine the activity of enzymes-cellulose of symbiotic origin, dominates. However, the intensity of the digestive processes, more expressed in the oral cavity of older workers, suggests that they are not only foragers, but also individuals and dominant in food processing compared to other members of the family in the conveyor of trophollaxis.

\subsection{Enteral Cellulose of Anacanthotermes turkestanicus Jacobson, 1904}

It is known that the food of Turkestan termite is wood or other materials based on cellulose. The intensity of cellulase activity in the intestine of $A$. turkestanicus has not been studied up to the present day.

The enzyme activity of the initial stage of cellulose hydrolysis. As an enzyme of the initial stage of carbohydrate hydrolysis, we determined the activity of exocellulase. It turned out that exocellulase is involved in the digestion of food polymers in the castes of termites-workers, nymphs and soldiers. Thus, cellulase activity in the intestinal tissue (intrinsic) is manifested at a very low level in all termites castes we studied. However, the activity of 
exocellulase in the intestinal cavity (symbiotic) increases 3.5 times in workers, 3.0 times in nymphs and 2.4 times in soldiers compared to that in intestinal tissue (Figure 4).

In addition, the intrinsic activity of this enzyme differed little in all three castes of termites, whereas the symbiotic activity in workers and nymphs was more expressed than in soldiers.

Therefore, in termites, regardless of caste, in the initial stages of cellulose digestion the enzymes in the intestinal cavity play a leading role, i.e. enzymes produced by symbiotic microorganisms. Symbiotic digestion is also manifested unequally among representatives of different castes.

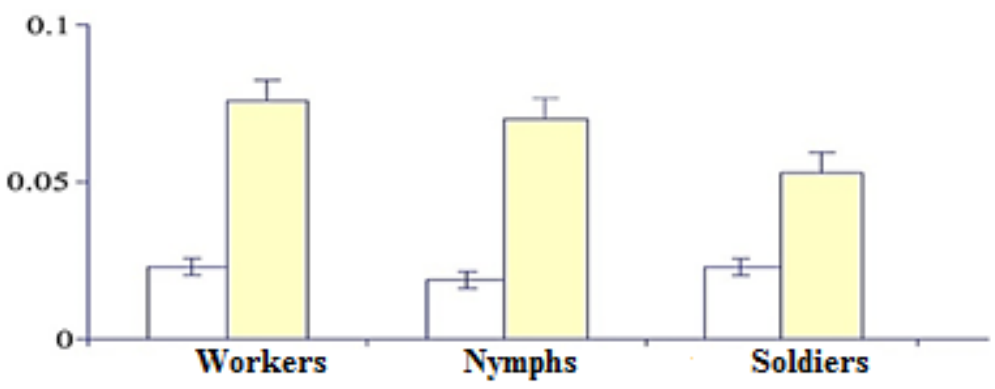

Figure 4. Activity of intrinsic (white columns) and symbiotic (yellow columns) cellulase in the intestine of various termites castes, along the ordinate axis-enzyme activity in arbitrary units

Enzyme activity of the final stage of cellulose hydrolysis. First of all, we found out that in the intestines of termites there is a spectrum of enzymes- $\beta$-glucosidases, participating in the final station of hydrolysis of oligomers (Table 2). In workers, the activity of all enzymes of the small intestine tissue involved in the splitting of cellulose hydrolysis products was weak (carboxymethyl cellulase, methyl cellulase) or practically absent (cellobiase), while it was well recorded in the intestinal contents. The activity of carboxymethylcellulase, methylcellulase, and cellobiase of symbiotic origin was 3.7, 2.4, and 3.0 times higher in workers than in intestinal tissue. In nymphs, the activity of $\beta$-glucosidase enzymes involved in the splitting of cellulose hydrolysis products was also manifested in trace amounts in the tissue of the small intestine, and the activity of symbiotic-cellulase enzymes prevailed over similar activities of its own enzymes (carboxymethylcellulase-2.4 times, methylcellulase-2.9 times and cellobiase-3 times).

Table 2. The activity of carbohydrases of the final stage of hydrolysis of carbohydrates $(\mu \mathrm{g} / \mathrm{min} / \mathrm{termite})$ in the tissue and small intestinal contents of the castes of termites-in workers, nymphs and soldiers $(\mathrm{M} \pm \mathrm{m} ; \mathrm{n}-5)$

\begin{tabular}{lllll}
\hline \multirow{2}{*}{ Ferment } & Digestion & \multicolumn{2}{c}{ Termites castes } \\
& & workers & nymphs & soldiers \\
\hline \multirow{2}{*}{ Carboxymethylcellulase } & \multirow{2}{*}{ Own symbiotic } & $0.038 \pm 0.010$ & $0.0271 \pm 0.002$ & $0.0181 \pm 0.002$ \\
Methylcellulase & & $0.130 \pm 0.022$ & $0.0661 \pm 0.005$ & $0.0541 \pm 0.006$ \\
& \multirow{2}{*}{ Own symbiotic } & $0.031 \pm 0.006$ & $0.0261 \pm 0.004$ & $0.0231 \pm 0.001$ \\
Cellobiase & & $0.134 \pm 0.043$ & $0.0761 \pm 0.008$ & $0.0531 \pm 0.006$ \\
& \multirow{2}{*}{ Own symbiotic } & $0.000 \pm 0.0$ & $0.0311 \pm 0.004$ & $0.0151 \pm 0.002$ \\
& & $0.0991 \pm 0.023$ & $0.0821 \pm 0.006$ & $0.0451 \pm 0.005$ \\
\hline
\end{tabular}

Note: P-indicator of the reliability of differences between the activities of same enzymes in the tissue and intestinal contents

As for the activity of digestive enzymes in soldiers, their hydrolytic ability remained the same tendency as in workers and nymphs, however, the activity of almost all same enzymes was at a lower level.

Consequently, not only the enzymes produced by microorganisms at the initial stage of hydrolysis, but also the symbiotic enzymes of the final stage of the hydrolysis of carbohydrates in workers, nymphs and soldiers in the digestion of cellulose are of decisive importance. The role of own tissue cellulases is insignificant. It is impossible 
not to notice that in this case, too, the hydrolytic activity of all the studied cellulases is manifested to the greatest extent among the workers compared to nymphs and soldiers.

So, the experiments demonstrate that enzymes of the initial and final stages of hydrolysis are involved in the digestion of cellulose in termites. Symbiotic digestion enzymes in all castes of termites play a major role in its digestion. Earlier there were studied the features of a number of termites from the Asian region to digest food with the help of cellulase symbiotes inhabiting the small intestine, as well as the quantitative ratio of cellulase activity in these species (Jujikov, 1979). Regarding Turkestan termite, such information is practically absent. Our data show that cellulose activity is less expressed in Turkestan termites than in other species. In addition, it was revealed that the digestive capacity of workers is more expressed than that of nymphs and soldiers. It is possible that such effective digestion of cellulose in workers is associated with more active nutritional and physical activity in comparison with nymphs and soldiers. Such activity requires high energy costs and, consequently, greater assimilation of the energetic material (cellulose). In addition, the high activity of cellulase is probably promoted by the fact that, usually, in termites, soldiers and nymphs of older ages do not feed themselves, but receive partially processed food from the workers.

In general, it can be concluded that the physiological characteristics of digestion of cellulose in Turkestan termite in the small intestine are associated with the evolutionary trophic adaptation of various castes of Turkestan termite to cellulose assimilation (Kuchkarova et al., 2006; Khamraev et al., 2007).

\subsection{Investigation of the Content of Oligocellulose in the Intestine of Termites in the Genus Anacanthotermes Jacobson, 1904}

The specific functional role of the hydrolytic enzymes responsible for the digestion of cellulose at various stages of its cleavage fed by wood lignin cellulose of insects in its own and symbiotic digestion is of both practical and fundamental interest. In addition, for the purposeful development of methods for the biocatalysis of cellulose, it is necessary to determine what the ratio of cellulose hydrolysis products in the intestines of termites is, with the content of the latter exclusively on cellulose.

The results of thin-layer chromatography (control sample, supernatant of the intestine of workers and winged females) showed that the spectrum of all investigated oligomers appears only in the control sample. In workers, along with a clear manifestation of the end product of oligodextrin hydrolysis, glucose is somewhat noticeable spots corresponding to cellotriose and cellopentose. It was marked, correlating with cellobiose and cellotetrosis, are completely absent. In general, the hydrolysis of intermediate oligomers in the intestine of working termites, as seen on the chromatogram, is quite effective.

In females, unlike workers in an aliquot of the intestinal homogenate supernatant only glucose appears. Any intermediate products of hydrolysis of cellulose oligomers are absent.

Thus, in the intestines of the termites the final product of cellulose hydrolysis is found from the studied oligodextrins-glucose, oligomers are either absent (females) or appear in trace amounts (workers).

As is known, the digestion of polysaccharides is carried out step by step, first the hydrolysis of polymers to oligoand dimers takes place, and then the latter are split into monomers. The final stage of the assimilation of cellulose in the small intestine is the absorption of monomers from the cavity into the circulation of the hemolymph. Our results show that the hydrolysis of cellulose transition product-cellodextrins: cellobiose, cellotriose, cellotetrose and cellopentose in workers and, especially, in females in the intestine is almost complete. In the studied castes and females, only the end product of cellulose decomposition, glucose is noticeably detected in the intestine. Therefore, we can conclude that for the digestion of oligomers, termites have an extremely effective system of exo and endocellulases.

It should be noted that in females, according to the chromatogram, the oligocellulase hydrolysis is more efficient compared to the workers. The reason for this manifestation may be the receipt of partial digested food by females from workers, along with the presence of effective enteral hydrolytic mechanisms of cellulose digestion. In the literature, there is evidence that females receive to some extent hydrolyzed food through proto or stomodeal trophallaxis. However, Turkestan termite has its own and symbiotic cellulose digestion systems (Kuchkarova et al., 2005). The dominant role of symbiotic microorganisms in the hydrolysis of cellulose is also noted in the species Reticulitermes fukienensis. The absence of cellulose hydrolysis products or their trace presence in the intestine, i.e. high polymer digestibility thus also speaks of the significant role of intestinal symbiotic microorganisms (Zhou et al., 2005; Wacneske et al., 2007) not only in hydrolysis, but also in the transformation of cellulose degradation products into other carbohydrates. 


\section{Conclusions}

A rather effective system of exo- and endocellulase was determined in the process of oligomer digestion by termites.

The causes of damage to wood by termites associated with carbohydrase activity of salivary and intestinal glands and symbiotic enzymes are characterized.

It was revealed that in the salivary glands of all castes of termites carboxycellulase and cellobiasis do not show activity.

It was marked the activity of the lactase enzyme in the salivary glands of termites in the genus Anacanthotermes.

\section{Acknowledgments}

This study was supported by the international projects carried out by the Institute of Zoology: P-122 «Development of management for the control of Turkestan termite, a major threat to cultural heritage in Central Asia».

\section{Conflict of interests}

The authors declare that there is no conflict of interests regarding the publication of this paper.

\section{References}

Abdullaev, I. I., Khamraev, A. Sh., Martius, Ch., Nurjanov, A. A., \& Eshchanov, R. A. (2002). Termites (Isoptera) in irrigated and Arid Landscapes of Central Asia (Uzbekistan). Sociobiology, 40(3), 605-614.

Baeva, V. G., Muminov, N. N., Lukyanova, S. N., \& Pokivaylov, A. A. (1993). Termites (Isoptera) of Tajikistan and measures on struggling with them. Dushanbe, 31.

Brune, A. (1998). Termite guts: The world's smallest bioreactors. J. Tibtech, 16, 16-21.

Emerson, A. E. (1980). Cretaceous insects from labrador a new genus and species of termite. (Isoptera: Hodotermitidae). Syche, 74(4), 276-289.

Gilyarov, M. S., \& Pravdina, F. N. (1984). Life of animals (Vol. 3, pp. 166-171). Moscow.

Jujikov, D. P. (1979). Termites of USSR (p. 225). Moscow: Publication of MSU.

Khamraev, A. Sh., Kuchkarova, L. S., Abdullaev, I. I., Ganieva, Z. A., \& Mirzaeva, G. S. (2010). The participation of enzymes of the salivary glands in carbohydrate digestion in various castes of termites. Uzbek Biology Journal, 4, 32-34. Tashkent.

Khamraev, A. Sh., Lebedeva, N. I., Abdullaev, I. I., Zhugunisov, T. I., \& Raina, A. K. (2006). Biology ecology and control of the Turkestan termite Anacanthotermes turkestsnicus, infesting structures of historical importance in Uzbekistan. $X V$ Congress of the International Union for the Study of Social Insects. Washington D.C., Poster.

Khamraev, A. Sh., Lebedeva, N. I., Zhugunisov, T. I., Abdullaev, I. I., Rakhmatullaev, A., \& Raina, A. K. (2007). Food Preferences of the Turkestan termite Anacanthotermes turkestanicus (Isoptera: Hodotermitidae). Socbiology, 50(2), 469-478.

Khamraev, A. Sh., Zhugunisov, T. I., \& Khanzafarova, N. V. (2004). Termites of Southern Aral Sea region of Uzbekistan. Bulletin of the Academy of Science of the RUz of Karakalpak branch, (1-2), 22-24. Nukus.

Krishna, K., \& David, A. (2013). Grimaldi, Krishna V., Michael S. Engel. Treatise on the Isoptera of the world. Bulletin of the American Museum of Natural History, 2(377), 2681.

Kuchkarova, L. S., Khamraev, A. Sh., Mirzaeva, G. S., \& Lebedeva, N. I. (2006). Features of chemical ecology of Turkestan termites. Collection of Republican Scientific and Practical Conferences Abstracts (p. 72). Tashkent.

Kuchkarova, L. S., Khamraev, A. Sh., Mirzaeva, G. S., Khanzafarova, N. V., \& Akhmerov, R. N. (2005). Analyse of carbohydrazic enzymes activity and qualitative food composition in Turkestan termites. International seminar abstract: "Termites of Central Asia: biology, ecology and control» (pp. 31-32). Tashkent.

Legendre, F., Michael, F. W., \& Grandcolas, P. (n. d.). Phylogenetic analyses of termite post embryonic sequences illuminate caste and developmental pathway evolution. Evolution \& Develop, 15(2), 146-157. 
Luppova, A. N. (1973). Entry of the types of termites of the USSR into the system of termites of the world. In the Collection: Termites Study and the Development of Anti-Thermal Measures (pp. 13-24). Ashkhabad

Raina, A. K., Bland, J. M., Dickens, J. C., Park, Y. I., \& Hollister, B. (2003). Pre-mating behavior of dilates of the Formosan subterranean termite and evidence for the presence of a contact sex pheromone. Journal of Insect Behavior, 16, 233-245.

Sapunov, V. B. (2008). Global dynamics of termite population: Modeling, control and role in green house effect. Proc. 6th Int. Conf. Urban Pests (pp. 389-393). Budapest.

Skirkyavichyus, A. V. (1986). Pheromone communication of insects (p. 292). Vilnus.

Ugolev, A. M. (1985). The evolution of digestion and the principles of the evolution of functionalism. Leningrad: Science, 544.

Ugolev, A. M., \& Iezuitova, N. N. (1969). Determination of the activity of invertase and other disaccharidosis. Study of the human digestive system. Leningrad: Science, 192-196.

Wacneske et al. (2007). Metagenomic and functional analysis of Hindgut microbiota of wood-feeding higher termites. Nature, 450, 560-565.

Weidner, H. (1960). Die Termite von Afghanistan, Iran und Irak. Abhandle. Naturwissenschaft., Vereins in Hamburg, 4, 43-70.

Zhou, B. C. R., Henderson, G., \& Laine, R. A. (2005). Screening method for inhibitors against Formosan termite B-glycosidase in vivo. Journal of Economic Entomology, 98, 41-46.

\section{Copyrights}

Copyright for this article is retained by the author(s), with first publication rights granted to the journal.

This is an open-access article distributed under the terms and conditions of the Creative Commons Attribution license (http://creativecommons.org/licenses/by/4.0/). 